\title{
Exogenous Ethylene Enhances Formation of Embryogenic Callus and Inhibits Embryogenesis in Cultures of Explants of Spinach Roots
}

\author{
Takuma Ishizaki, ${ }^{1}$ Fuminori Komai, and Kiyoshi Msuda \\ Graduate School of Agriculture, Hokkaido University, Sapporo 060-8589, Japan \\ Chiaki Megumi \\ Faculty of Agriculture, Hokkaido University, Sapporo 060-8589, Japan
}

AdDitional INDEX wORDs. ethephon, silver nitrate, AVG, tissue culture, somatic embryos, embroids

\begin{abstract}
Effects of ethephon, $\mathrm{AgNO}_{3}$, and AVG on formation of embryogenic callus and somatic embryogenesis were examined in cultures of explants of spinach (Spinacia oleracea L. 'Nippon') roots. At $10 \mu \mathrm{M}$, ethephon more than doubled the frequency of formation of embryogenic callus as compared to that in cultures without ethephon. Silver nitrate at 10 $\mu_{\mathrm{M}}$ and AVG at $1 \mu_{\mathrm{M}}$ each inhibited formation of embryogenic callus but neither reduced the growth rate of established callus. When ethephon was applied at $10 \mu_{\mathrm{M}}$ during embryogenesis, it completely inhibited embryo development. By contrast, $\mathrm{AgNO}_{3}$ at $10 \mu \mathrm{M}$ markedly increased the number of embryos. Results suggest that ethylene might be essential as a plant hormone for formation of embryogenic callus but inhibits somatic embryogenesis per se in cultures of explants of spinach roots. Chemical names used: 2-chloroethylphosphonic acid (ethephon), silver nitrate $\left(\mathrm{AgNO}_{3}\right)$, aminoethoxyvinylglycine (AVG).
\end{abstract}

Ethylene is a plant hormone involved in the regulation of various aspects of plant growth and differentiation. Many studies have been published on the effects of this compound on organogenesis and somatic embryogenesis in plant tissue cultures (Krikorian 1995).

There have been numerous reports demonstrating that exogenously supplied ethylene inhibits somatic embryogenesis and some ethylene inhibitors have been shown to have a promotive effect. For example, addition of ethylene or of the ethyleneproducing compound ethephon prevents embryogenesis in carrot (Daucus carota L.) (Tisserat and Murashige 1977, Wochok and Wetherell 1971), while $\mathrm{AgNO}_{3}$, a potent inhibitor of the actions of ethylene (Beyer 1976), enhances production of embryogenic callus with a typical friable texture in corn (Zea mays L.) (Songstad et al. 1991, Vain et al. 1989), as well as embryogenesis in carrot (Roustan et al. 1990). Furthermore, inhibitors of ethylene biosynthesis, such as AVG and cobalt ions, stimulate somatic embryogenesis in white spruce (Picea glauca (Moench) Voss) (Kong and Yeung 1994) and in certain genotypes of soybean [Glycine max (L.) Merrill] with limited regenerative ability (Santos et al. 1997).

It has also been demonstrated that application of ethylene promotes somatic embryogenesis. For example, in orange [Citrus sinensis (L.) Osbeck], a low concentration of ethephon $\left(0.1 \mathrm{mg} \cdot \mathrm{L}^{-1}\right)$ greatly enhances embryogenesis (Kochba et al. 1978) and in alfalfa (Medicago sativa L.), ethylene is required both for callus growth and for somatic embryogenesis (Kepczynski et al. 1992). In coffee (Coffea canephora Pierre ex Froehn.), somatic embryogenesis is inhibited by ethylene inhibitors and enhanced by exogenous gaseous ethylene (Hatanaka et al. 1995). These results are apparently contradictory, but they demonstrate that the effects

Received for publication 28 Jan. 1998. Accepted for publication 24 Aug. 1999 We thank N. Kasai, Hokkaido University, for excellent technical assistance and T. Harada, Hokkaido University, for continuing interest and encouragement. This work was supported by grant in aid 09660016 rom the Ministry of Education of Japan. The cost of publishing this paper was defrayed in part by the payment of page charges. Under postal regulations, this paper therefore must be hereby marked advertisement solely to indicate this fact.

${ }^{1}$ E-mail: gohho@res.agr.hokudai.ac.jp. of ethylene and of ethylene inhibitors on somatic embryogenesis differ among plant species and among various types of tissues.

Somatic embryogenesis of spinach (Spinacia oleracea) was first reported by Xiao and Branchard (1993), and a protocol for regeneration of plants from root explants was established subsequently by Komai et al. (1996a, 1996b, 1996c). Tests of effects of various nutritional and hormonal supplements revealed that application of gibberellic acid $\left(\mathrm{GA}_{3}\right)$ in combination with a relatively low concentration of fructose $(29 \mathrm{~mm})$ was beneficial for formation of embryogenic callus in cultures of root explants (Komai et al. 1996a, 1996c). However, the effects of exogenous ethylene on embryogenesis remained to be investigated.

The following research was conducted to characterize the role of ethylene in somatic embryogenesis in spinach with the goal of improving the efficiency of regeneration of plants from root explants. Effects of ethephon, $\mathrm{AgNO}_{3}$, and $\mathrm{AVG}$ on formation of embryogenic callus and somatic embryogenesis using established cultures of root explants from spinach seedlings were investigated (Komai et al. 1996a).

\section{Materials and Methods}

Plant material. Root explants were prepared from aseptically grown seedlings of 'Nippon' spinach as follows. Seeds were surface sterilized by dipping them in $70 \%(\mathrm{v} / \mathrm{v})$ ethanol for $30 \mathrm{~s}$ and then soaking them for $1 \mathrm{~h}$ in a solution of $10 \%$ sodium hypochlorite (active chlorine, $1 \%$ ) that contained $0.1 \%$ polyoxyethylene sorbitan monolaurate (Tween 20). The seeds were rinsed with sterile distilled water and then placed in glass jars (60 mm in diameter $\times 110 \mathrm{~mm}$ in height) containing $25 \mathrm{~mL}$ of semisolid medium that contained half-strength Murashige and Skoog (MS) salts (Murashige and Skoog 1962), complete MS vitamins, sucrose at $20 \mathrm{~g} \cdot \mathrm{L}^{-1}$, and agar at $7 \mathrm{~g} \cdot \mathrm{L}^{-1}(\mathrm{pH}$ 5.7). The seeds were incubated at $25^{\circ} \mathrm{C}$ in darkness. Ten to fourteen days later, root explants $\approx 5 \mathrm{~mm}$ in length were excised from the seedlings.

Callus induction. For induction of callus the protocol of Komai et al. (1996a) was used with minor modification. Root 


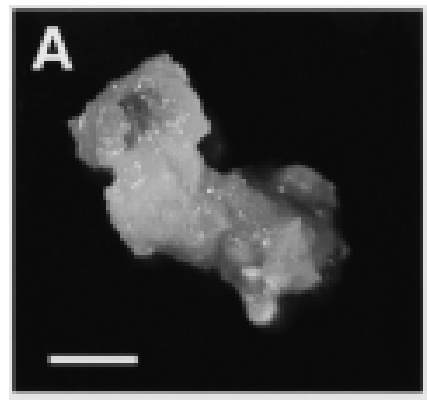

B
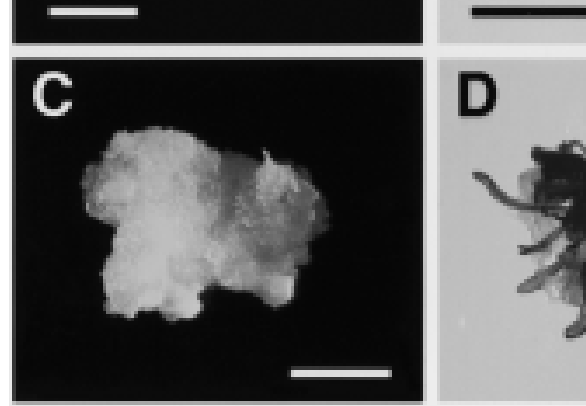

D

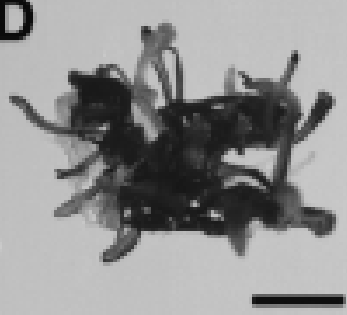

Fig. 1. Typical appearance of embryogenic callus derived from explants of spinach roots and of developing somatic embryos on embryogenic callus. (A) Callus formed on medium that contained $10 \mu \mathrm{M}$ NAA and $0.1 \mu \mathrm{M} \mathrm{GA}_{3}$. (B) Somatic embryos differentiated from callus on medium without growth regulators. (C) Suppression of embryogenesis from embryogenic callus after transfer to medium that contained $10 \mu \mathrm{M}$ ethephon. (D) Enhanced embryogenesis from embryogenic callus after transfer to medium that contained $10 \mu \mathrm{M} \mathrm{AgNO}_{3}$. Bars: $\mathrm{A}$ and $\mathrm{C}=2 \mathrm{~mm}$; $\mathrm{B}$ and $\mathrm{D}=5 \mathrm{~mm}$.

explants were placed in a $100 \mathrm{~mL}$ Erlenmeyer flask containing 20 $\mathrm{mL}$ of callus-induction (CI) medium, consisting of half-strength MS salts, complete MS vitamins, fructose at $5.4 \mathrm{~g} \cdot \mathrm{L}^{-1}$, and $10 \mu \mathrm{M}$ 1-naphthaleneacetic acid (NAA), and $0.1 \mu \mathrm{m}$ gibberellic acid $\left(\mathrm{GA}_{3}\right)$. The medium was adjusted to $\mathrm{pH} 5.7$ with $0.1 \mathrm{~mol} \cdot \mathrm{L}^{-1} \mathrm{HCl}$ and solidified with agar at $7 \mathrm{~g} \cdot \mathrm{L}^{-1}$. To examine the effects of ethylene on formation of embryogenic callus, ethephon (Wako Pure Chemical Co., Osaka, Japan), $\mathrm{AgNO}_{3}$, and AVG (Sigma, St. Louis, Mo.) were added to the CI medium. Ethephon and $\mathrm{AgNO}_{3}$ were added at $0,1,10$, or $100 \mu \mathrm{M}$, while AVG was added at 0,1 , or $10 \mu \mathrm{M}$. Ethephon and AVG were filter-sterilized and added to the medium after the medium autoclaved. Cultures were incubated at $25^{\circ} \mathrm{C}$ with a $16-\mathrm{h}$ photoperiod of $70 \mu \mathrm{mol} \cdot \mathrm{m}^{-2} \cdot \mathrm{s}^{-1}$ at the level of flasks (measured using a LI-185B quantum photometer; LI-COR, Lincoln, Neb.) provided by cool-white fluorescent lamps (FLR40SW/M/36; Mitsubishi Osram, Yokohama, Japan). To estimate callus growth, fresh weights of calli were recorded after 4 weeks.

ESTIMATING THE FREQUENCY OF EMBRYOGENIC CALLUS FORMATION. After root explants had been cultured 4 weeks on CI medium, the embryogenic capacity of each callus was examined by transferring entire explants with developing calli to a $100 \mathrm{~mL}$ Erlenmeyer flask containing $20 \mathrm{~mL}$ of embryo-production (EP) medium consisting of half-strength MS salts, MS vitamins, sucrose at $20 \mathrm{~g} \cdot \mathrm{L}^{-1}$, and agar at $7 \mathrm{~g} \cdot \mathrm{L}^{-1}(\mathrm{pH}$ 5.7). The percentage of calli that formed embryos was recorded 4 weeks later. In this report we refer to callus as embryogenic callus that would eventually develop somatic embryos on a medium without growth regulators. Since more than $90 \%$ of embryos had developed to the late torpedo stage or formed young seedlings by the time we examined the cultures, embryogenic calli were easily distinguished by their appearance from calli that had only increased in size.
EFFECTS OF ETHYLENE AND ETHYLENE INHIBITORS ON SOMATIC EMBRYOGENESIS. Embryogenic callus was obtained by culturing explants of spinach roots on CI medium for 4 weeks. To examine the effects of ethylene on somatic embryogenesis, we cultured these calli in a $100 \mathrm{~mL}$ Erlenmeyer flask containing $20 \mathrm{~mL}$ of EP medium supplemented with ethephon or $\mathrm{AgNO}_{3}$ at $0,1,10$, or 100 $\mu \mathrm{M}$. Ethephon was filter-sterilized and added to the autoclaved medium just before the medium began to solidify. Cultures were incubated at $25^{\circ} \mathrm{C}$ with a $16-\mathrm{h}$ photoperiod of $70 \mu \mathrm{M} \cdot \mathrm{m}^{-2} \cdot \mathrm{s}^{-1}$ from fluorescent lamps. Four weeks after transfer of calli to EP medium, we determined the number of embryos that had formed by dispersing calli in water using forceps. Embryos were counted directly or under a dissecting microscope. The percentages of calli that had differentiated embryos were also calculated.

EXPERIMENTAL DESIGN AND STATISTICAL ANALYSIS. Five pieces of root explants and callus tissues were transferred to test media in each culture vessel. Each treatment consisted of 25 explants and each experiment was repeated three to five times. Means and standard errors were calculated based on the data obtained from repeated experiments.

\section{Results}

EFFECTS OF ETHEPHON ON EMBRYOGENIC CALLUS FORMATION. Calli developed from explants of spinach roots in the presence of $0.1 \mu \mathrm{M} \mathrm{GA}$ plus $10 \mu \mathrm{M}$ NAA (Fig. 1A) and differentiated into somatic embryos after transfer to medium without growth regulators (Fig. 1B) as reported previously (Komai et al. 1996a). Moreover, the medium effectively supported the formation of embryogenic callus (Komai et al. 1996b, 1996c). Using this system, we examined the effects of an exogenous generator of ethylene, ethephon, on formation of embryogenic callus. Ethep-

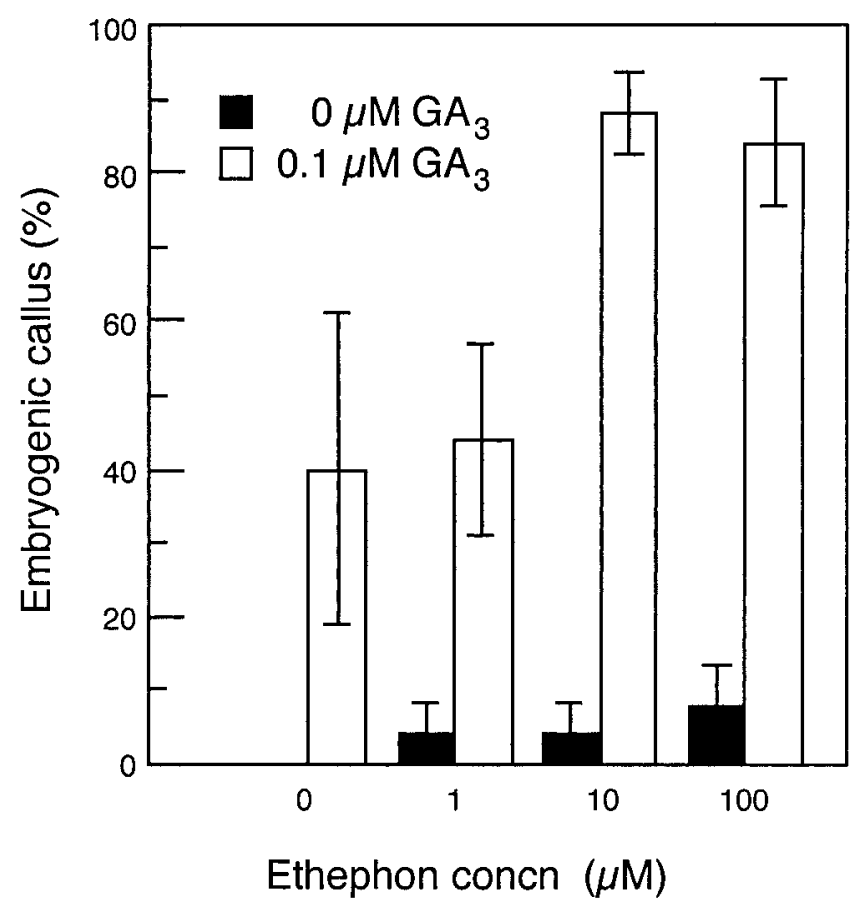

Fig. 2. Effects of ethephon on the formation of embryogenic callus from explants of spinach roots. Explants were cultured for 4 weeks on the medium that contained $10 \mu \mathrm{M}$ NAA with or without $0.1 \mu \mathrm{M} \mathrm{GA}_{3}$ and supplemented with ethephon at 0 to $100 \mu \mathrm{M}$. Calli were then transferred to medium without growth regulators for identification of embryogenic callus. Embryogenic callus was identified after 4 weeks culture. Vertical bars represent \pm 1 SE. $(n=3)$. 
Table 1. Effects of $\mathrm{AgNO}_{3}$ and $\mathrm{AVG}$ on growth of callus and formation of embryogenic callus in cultures of explants of spinach roots. Explants were cultured on CI medium supplemented with $\mathrm{AgNO}_{3}$ or $\mathrm{AVG}$ for 4 weeks.

\begin{tabular}{|c|c|c|c|c|}
\hline \multirow{2}{*}{$\begin{array}{l}\text { Concn } \\
(\mu \mathrm{M})\end{array}$} & \multicolumn{2}{|c|}{$\begin{array}{l}\text { Fresh wt } \\
\text { (mg/callus) }\end{array}$} & \multicolumn{2}{|c|}{$\begin{array}{c}\text { Embryogenic callus }^{\mathrm{y}} \\
(\%)\end{array}$} \\
\hline & $\mathrm{AgNO}_{3}$ & AVG & $\mathrm{AgNO}_{3}$ & AVG \\
\hline 0 & $12.1 \pm 3.2$ & $14.6 \pm 2.9$ & $52.0 \pm 12.3$ & $46.7 \pm 4.3$ \\
\hline 1 & $13.4 \pm 4.7$ & $9.5 \pm 3.4$ & $44.0 \pm 14.2$ & $4.0 \pm 2.8$ \\
\hline 10 & $30.2 \pm 6.7$ & $19.5 \pm 7.9$ & $0.0 \pm 0.0$ & $0.0 \pm 0.0$ \\
\hline 100 & $11.8 \pm 4.6$ & $\mathrm{ND}^{\mathrm{x}}$ & $0.0 \pm 0.0$ & $\mathrm{ND}^{\mathrm{x}}$ \\
\hline
\end{tabular}

${ }^{\mathrm{z}}$ Mean \pm 1 SE. $(\mathrm{n}=5)$.

yMean \pm 1 SE $(n=3)$.

${ }^{\mathrm{x}} \mathrm{ND}=$ not determined.

hon had little promotive effect in the absence of $\mathrm{GA}_{3}$ but, in the presence of $0.1 \mu \mathrm{M} \mathrm{GA}$, it stimulated considerable formation of embryogenic callus (Fig. 2). All calli were very friable, regardless of the presence or absence of $\mathrm{GA}_{3}$, and application of ethephon had no effect on the appearance of calli. The most effective concentration of ethephon for formation of embryogenic callus was $10 \mu \mathrm{M}$ but no inhibition was observed at a higher concentration (Fig. 2). Finally, more than four times as many somatic embryos developed from callus formed on medium that contained $10 \mu \mathrm{M}$ ethephon than regenerated from callus grown without ethephon (data not presented).

EFFECTS OF $\mathrm{AgNO}_{3}$ AND AVG ON EMBRYOGENIC CALLUS FORMATION. At $10 \mu \mathrm{M}, \mathrm{AgNO}_{3}$ completely suppressed development of embryogenic callus, whereas it more than doubled the rate of callus growth. At higher concentrations, $\mathrm{AgNO}_{3}$ suppressed embryogenesis and reduced the growth rate of callus (Table 1), possible because of the toxicity of the metal ions. AVG almost completely inhibited formation of embryogenic callus at $1 \mu \mathrm{M}$ (Table 1). The inhibitory effect of $1 \mu \mathrm{M}$ AVG on the formation of embryogenic callus was reversed up to $76 \%$ by application of ethephon at $10 \mu \mathrm{M}$. No significant reductions in the rate of callus growth were recognized over the range of AVG concentrations tested.

EFFECTS OF ETHEPHON AND $\mathrm{AgNO}_{3}$ ON EMBRYOGENESIS FROM CALLI. In contrast to the promotive effects of ethephon on the formation of embryogenic callus, addition of ethephon to EP medium strongly inhibited differentiation of embryos from calli (Figs. 1C and 3), and at $100 \mu \mathrm{M}$ no differentiation was observed at all. Concomitantly, the percentage of calli showing evidence of embryogenesis was reduced by application of ethephon. In accordance with these observations, $\mathrm{AgNO}_{3}$ at concentrations up to 10 $\mu \mathrm{M}$ markedly increased the numbers of embryos that developed from embryogenic calli (Figs. 1D and 3). Addition of $10 \mu \mathrm{M}$ $\mathrm{AgNO}_{3}$ to EP medium resulted in formation of about three times more embryos as compared with controls. At higher concentrations, $\mathrm{AgNO}_{3}$ reduced the numbers of visible embryos. The percentage of calli that formed embryos did not change appreciably over the range of concentrations of $\mathrm{AgNO}_{3}$ tested. AVG at concentrations up to $10 \mu \mathrm{M}$ had a minimal promotive effect on embryogenesis (data not presented).

\section{Discussion}

Somatic embryogenesis from root tissue of spinach requires both the formation of embryogenic callus from root explants and subsequent embryogenesis from the callus. These two processes have different growth regulator requirements. An exogenous supply of $\mathrm{GA}_{3}$ in the presence of NAA promotes the first process, whereas the latter process does not require the exogenous supply of growth regulators (Komai et al. 1996a). In the present investigation, the addition of ethephon to the CI medium enhanced development of embryogenic callus. By contrast, addition of $\mathrm{AgNO}_{3}$ or $\mathrm{AVG}$ reduced the rate of formation of embryogenic callus without reducing the growth rate of callus. Silver nitrate and AVG at $10 \mu \mathrm{M}$ and $1 \mu \mathrm{M}$, respectively, completely inhibited
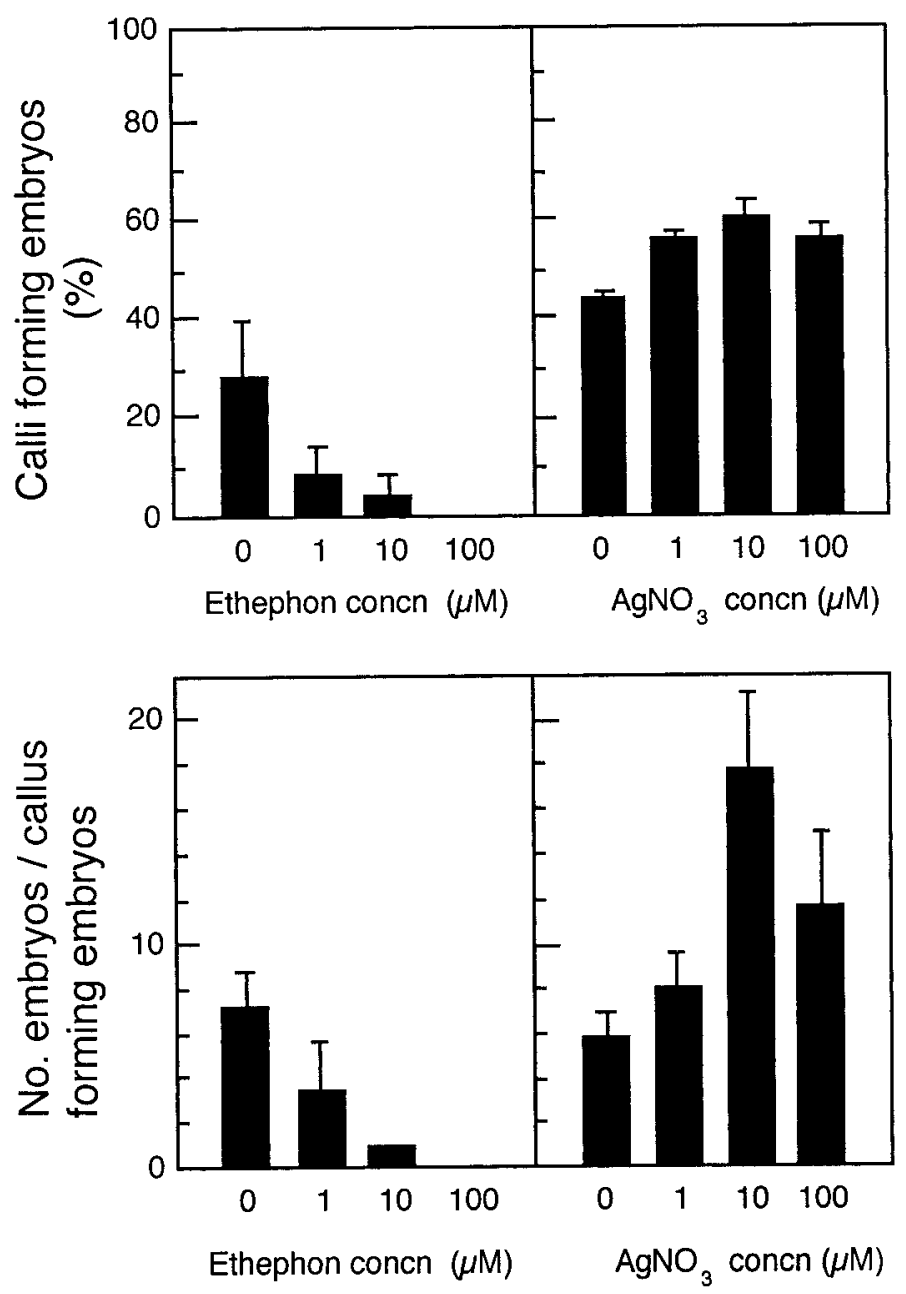

Fig. 3. Effects of ethephon and $\mathrm{AgNO}_{3}$ on embryogenesis from callus derived from explants of spinach roots. Calli that formed during a 4-week incubation period on medium that contained $10 \mu \mathrm{M}$ NAA and $0.1 \mu \mathrm{M} \mathrm{GA}_{3}$ were transferred to medium without growth regulators but supplemented with ethephon (left) or $\mathrm{AgNO}_{3}$ (right). Calli were cultured for an additional 4 weeks, and the percentage of calli that developed embryos and the average number of embryos per callus were determined. Vertical bars represent \pm 1 SE. $(n=5)$. 
formation of embryogenic callus from explants of spinach roots. These concentrations are similar to those at which ethylene inhibitors are effective in other plant tissue culture systems (Goh et al. 1997, Hatanaka et al. 1995, Kong and Yeung 1994, Lee et al. 1997, Roustan et al. 1990, Songstad et al. 1991, Vain et al. 1989). Our results suggest that ethylene is essential for development of embryogenic callus on explants of spinach roots and that application of ethylene promotes conditions that are favorable for initiation of somatic embryogenesis.

Enhancement of formation of embryogenic callus by ethephon was observed only when $\mathrm{GA}_{3}$ was also supplied exogenously to cultures. Application of $\mathrm{GA}_{3}$ plus an auxin to the CI medium effectively enhances the formation of embryogenic callus (Komai et al. 1996a, Xiao and Branchard 1993). Moreover, ethephon could not replace an exogenous supply of $\mathrm{GA}_{3}$. With respect to the interactions between the effects of ethylene and those of gibberellins, there is some evidence that gibberellins mediate, to some extent, the effects of ethylene. Thus, for example, ethylene promotes growth of rice (Oryza sativa L.) seedlings by increasing the responsiveness of the internodal tissue to gibberellin (Hoffmann-Benning and Kende 1992). In young rice seedlings, ethylene stimulates elongation of leaves by increasing the responsiveness to $\mathrm{GA}_{1}$ and the turnover of $\mathrm{GA}_{1}$ (Furukawa et al. 1997). Thus, it is likely that enhancement of the formation of embryogenic callus by exogenous ethylene is due to an increase of the responsiveness of cells to gibberellin. Moreover, spinach root tissues might be responsive to gibberellin only in the presence of ethylene.

Addition to the medium of ethephon during embryogenesis decreased the number of embryos formed on calli derived from root explants, and the addition of $\mathrm{AgNO}_{3}$ at 10 to $100 \mu \mathrm{M}$ increased the number of embryos. These observations suggest that ethylene might act to inhibit somatic embryogenesis in spinach. These findings agree with the results of many previous studies that indicate ethylene has an inhibitory effect on somatic embryogenesis. The limited promotive effect of $10 \mu \mathrm{M}$ AVG on embryogenesis from spinach callus might have been due to incomplete inhibition of the biosynthesis of ethylene because of the low concentration of AVG employed or decomposition of this inhibitor.

This report provides a clear demonstration of the promotive and inhibitory actions of ethylene on in vitro somatic embryogenesis in explants of spinach roots. It also provides an improved protocol for in vitro regeneration of plants from spinach tissue that might be applicable to other species. However, it remains to be determined whether the development-dependent inhibition and stimulation that we observed involves production of ethylene, the sensitivity of the tissue to ethylene and/or interactions with the effects of other growth regulators.

\section{Literature Cited}

Beyer, E.M. 1976. A potent inhibitor of ethylene action in plants. Plant Physiol. 58:268-271.

Furukawa, K., Y.Y. Yang, I. Honda, T. Yanagisawa, A. Sakurai, N.
Takahashi, and Y. Kamiya. 1997. Effects of ethylene and gibberellins on the elongation of rice seedlings (Oryza sativa L.). Biosci. Biotech. Biochem. 61:864-869.

Goh, C.J., S.K. Ng, P. Lakshmanan, and C.S. Loh. 1997. The role of ethylene on direct shoot bud regeneration from mangosteen (Garcinia mangostana L.) leaves cultured in vitro. Plant Sci. 124:193-202.

Hatanaka, T., E. Sawabe, T. Azuma, N. Uchida, and T. Yasuda. 1995. The role of ethylene in somatic embryogenesis from leaf discs of Coffea canephora. Plant Sci. 107:199-204.

Hoffmann-Benning, S. and H. Kende. 1992. On the role of abscisic acid and gibberellin in the regulation of growth in rice. Plant Physiol. 99:1156-1161.

Kepczynski, J., B.D. Mckersie, and D.C.W. Brown. 1992. Requirement of ethylene for growth of callus and somatic embryogenesis in Medicago sativa L. J. Expt. Bot. 43:1199-1202.

Kochba, J., P. Spiegel-Roy, H. Neumann, and S. Saad. 1978. Stimulation of embryogenesis in Citrus ovular callus by ABA, ethephon, CCC, and alar and its suppression by GA. Z. Pflanzenphysiol. Bd. 89:427-432.

Komai, F., I. Okuse, and T. Harada. 1996a. Effective combination of plant growth regulators for somatic embryogenesis from spinach root segments. J. Jpn. Soc. Hort. Sci. 65:559-564.

Komai, F., I. Okuse, and T. Harada. 1996b. Somatic embryogenesis and plant regeneration in culture of root segments of spinach (Spinacia oleracea L.). Plant Sci. 113:203-208.

Komai, F., I. Okuse, K. Saga, and T. Harada. 1996c. Improvement on the efficiency of somatic embryogenesis from spinach root tissues by applying various sugars. J. Jpn. Soc. Hort. Sci. 65:67-72.

Kong, L. and E.C. Yeung. 1994. Effects of ethylene and ethylene inhibitors on white spruce somatic embryo maturation. Plant Sci. 104:71-80.

Krikorian, A.D. 1995. Hormones in tissue culture and micropropagation, p. 774-796. In: P.J. Davies (ed.). Plant hormones. Kluwer Academic Publishers, The Netherlands.

Lee, T., M.E.E. Huang, and E.C. Pua. 1997. High frequency shoot regeneration from leaf disc explants of garland chrysanthemum (Chrysanthemum coronarium L.) in vitro. Plant Sci. 126:219-226.

Murashige, T. and F. Skoog. 1962. A revised medium for rapid growth and bioassays with tobacco tissue cultures. Physiol. Plant. 15:473-497.

Roustan, J.P., A. Latche, and J. Fallot. 1990. Control of carrot somatic embryogenesis by $\mathrm{AgNO}_{3}$, an inhibitor of ethylene action: Effect on arginine decarboxylase activity. Plant Sci. 67:89-95.

Santos, K.G.B., E. Mundstock, and M.H. Bodanese-Zanettini. 1997. Genotype-specific normalization of soybean somatic embryogenesis through the use of an ethylene inhibitor. Plant Cell Rpt. 16:859-864.

Songstad, D.D., C.L. Armstrong, and W.L. Petersen. 1991. $\mathrm{AgNO}_{3}$ increases type II callus production from immature embryos of maize inbred B73 and its derivatives. Plant Cell Rpt. 9:699-702.

Tisserat, B. and T. Murashige. 1977. Effects of ethephon, ethylene, and 2,4-dichlorophenoxyacetic acid on asexual embryogenesis in vitro. Plant Physiol. 60:437-439.

Vain, P., H. Yean, and P. Flament. 1989. Enhancement of production and regeneration of embryogenic type II callus in Zea mays L. by $\mathrm{AgNO}_{3}$. Plant Cell, Tissue, Org. Cult. 18:143-151.

Wochok, Z.S. and D.F. Wetherell. 1971. Suppression of organized growth in cultured wild carrot tissue by 2 -chloroethylphosphonic acid. Plant Cell Physiol. 12:771-774.

Xiao, X.G. and M. Branchard. 1993. Embryogenesis and plant regeneration of spinach (Spinacia oleracea L.) from hypocotyl segments. Plant Cell Rpt. 13:69-71. 